\title{
Common reptiles unaffected by connectivity or condition in a fragmented farming landscape
}

\author{
ADAM J. SCHUTZ AND DON A. DRISCOLL* \\ School of Biological Sciences, Flinders University, GPO Box 2100, Adelaide, South Australia, Australia
}

\begin{abstract}
Species need to disperse at a broad range of spatial scales, the recognition of which has spawned programmes such as Wildlands and WildCountry that aim to restore large-scale connectivity. To achieve connectivity, a first step is to understand how wildlife uses existing remnants. In this study we examine the effect of remnant isolation and condition on the reptile fauna of fragmented mallee habitats in southern Australia. In three replicate landscapes we use pitfall traps to survey reptiles in five landscape elements: Conservation Park, connected, disconnected and isolated fragments, and the agricultural matrix. Reptile species richness, abundance, abundance of snakes, skinks and the 10 most common species had no significant association with landscape elements, excluding the matrix. This was despite a substantial reduction in plant species richness in the fragments, particularly of shrubs. Only seven individual reptiles were captured in the matrix, most on one site with deep sandy soils. The farmland on clay soils appeared to be relatively impermeable for reptiles, although four species could traverse $100 \mathrm{~m}$ of cleared sand-dune. The lack of an isolation effect suggests that populations in remnants are persistent, or that occasional dispersal by common reptiles maintains populations. In contrast with common species, fewer rare species were captured in remnants compared with the Conservation Park, implying that some species may be entirely excluded from the remnants. Our study suggests that the spatial configuration and condition of the fragments sustain populations of many common reptile species. Remnants will therefore be invaluable as attempts are made to restore landscape-scale permeability. However, additional conservation effort should be made to restore plant species that have been lost from the agricultural landscape. Future research should aim to better define the suite of reptile species that may not be able to use the remnants at all.
\end{abstract}

Key words: Eucalyptus, habitat fragmentation, mallee, patch isolation, remnant vegetation.

\section{INTRODUCTION}

Habitat loss and fragmentation is of serious concern around the world for its effects on species persistence (With et al. 1999; Hobbs 2001; FerraZ et al. 2003; Krauss et al. 2003; Swihart et al. 2003; Williams et al. 2003; Sumner et al. 2004; Driscoll \& Weir 2005; Harper et al. 2005; Wiegand et al. 2005). Fragmentation and habitat loss can subdivide a population by eliminating dispersal (McCoy \& Mushinsky 1994; Stow et al. 2001) and so produce numerous small populations. Populations of smaller size are at greater risk of local extinction through demographic, genetic and stochastic processes (Watson 2002; Segelbacher et al. 2003; Stockwell et al. 2003; Williams et al. 2003; Reed 2004; Sumner et al. 2004). Furthermore, the loss or reduction in abundance of one species from fragments can have a cascading effect on other species, potentially altering community composition (Patten \&

\footnotetext{
${ }^{\star}$ Corresponding author. Present address: Fenner School of Environment and Society, Australian National University, Canberra, ACT 0200, Australia (Email: don.driscoll@anu.edu.au)

Accepted for publication August 2007.
}

Bolger 2003; Borrvall \& Ebenman 2006). Habitat loss and fragmentation therefore results in considerable loss of species (Watson 2002; Ferraz et al. 2003; Segelbacher et al. 2003; Swihart et al. 2003).

There is debate about the relative importance for species survival of the spatial arrangement of patches compared with the condition of remnant vegetation (Harrison \& Bruna 1999). For example, Hobbs (2001) argued that spatial aspects of modified landscapes had received more attention than warranted, suggesting that internal conditions of fragments may exert an even greater influence. For example, in Tasmania, Australia, Jellinek et al. (2004) found that lizard species richness and abundance were affected by vegetation type, structure and environmental variables, but not habitat size or edge effects. This debate has been allowed to continue partly because it is often difficult to separate the effects of isolation from confounding factors, where the most isolated sites are often in the worst condition (Ewers \& Didham 2006).

Agricultural practices involve numerous processes that can significantly influence the internal condition of fragments. Tilling paddocks and nutrient or herbicide application can potentially have a serious effect on 
neighbouring native vegetation (Boutin \& Jobin 1998). Grazing by domestic stock can alter vegetation structure and community composition (Smith et al. 1996; Bromham et al. 1999; Read 2002; Landsberg et al. 2003). Yates et al. (2000) found that heavily grazed woodlands had significantly less logs, woody debris, litter and perennial shrubs and herbs, while there was an increase in exotic annual cover. This resulted in considerable alterations to the soil's physical and chemical properties as well as the microclimate of the grazed environment. Grazing also has the potential to influence tree regeneration (Fischer et al. 2005).

The impacts of grazing on plant structure and the abiotic environment in turn influence the fauna (Bromham et al. 1999; Hartley et al. 2003; James 2003; Nash et al. 2004; Martin \& Possingham 2005). The effect of grazing on reptiles can have both positive and negative effects on reptile abundance and community composition (Fabricius et al. 2003; Beever \& Brussard 2004). In one study, reptiles were observed to be largely resilient to the effects of short-term grazing with only some species-specific responses (Read 2002). In contrast, James (2003) compared lightly and heavily grazed sites and found that abundance and species richness of diurnal reptiles were significantly lower in the heavily grazed habitat, whereas nocturnal species were unaffected. Therefore, the response of reptiles depends on the grazing regime, the study region and the individual characteristics of the reptile species.

The matrix can also be an important aspect when considering the effect of fragmentation (Driscoll 2005), because it has the potential to influence dispersal ability (Berry et al. 2005). Fischer et al. (2005) found that the matrix not only helped facilitate dispersal of some reptiles between fragments, but could act as a habitat for some species. Understanding the extent of use of the matrix is therefore a necessary step for detecting population fragmentation in fragmented landscapes (Ricketts 2001; Kupfer et al. 2006). This approach contrasts with early meta-population models, which assumed the matrix was simply inhospitable terrain (Levins 1970).

The Eyre Peninsula of South Australia contains a small number of large reserves (8 reserves $>5000$ ha in size) set in a highly cleared landscape. However, the farmland has an extensive linear sand-dune system, in which most of the dune-tops have not been cleared. This has resulted in a landscape with linear fragments $30-100 \mathrm{~m}$ wide and frequently $1-3 \mathrm{~km}$ long which occupy a continuum of isolation levels, but have relatively homogeneous patch condition. The combination of similar patch condition over a range of isolation levels enables isolation to be studied without confounding with condition.

Understanding the potential for linear dune-top remnants to provide connectivity across the landscape

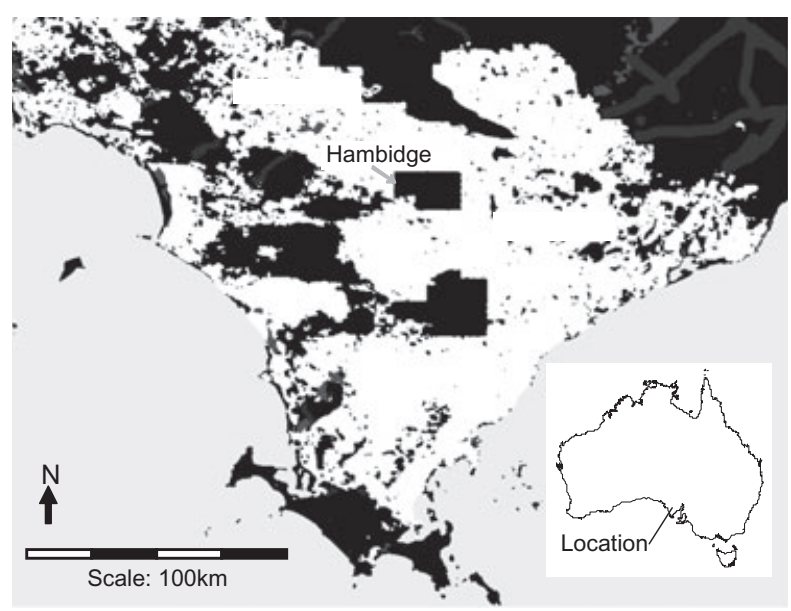

Fig. 1. South Australia's Eyre Peninsula, showing Hambidge Conservation Park. Black areas are remnant vegetation, white areas are cleared land.

is particularly important. An ability to permeate through the landscape is critical for species to adapt to climate change, to access spatially variable resources and for normal evolutionary processes to continue (Soulé et al. 2004). Large-scale connectivity, up to continental scales, are now on the agenda of conservation organizations and governments (Soule \& Terborgh 1999), and this includes plans for ensuring connecting links to the large reserves on the Eyre Peninsula through the WildCountry and NatureLinks programmes (Recher 2003; DEH 2004). Understanding the potential for linear remnants to provide connectivity across the agricultural landscapes is an essential first step for planning large-scale connectivity.

Given the imperative to understand connectivity across the Eyre Peninsula, we address four questions:

1. How do reptile species respond to increasing isolation of linear remnants?

2. Are there differences in condition (vegetation structure and community composition) between conservation park habitat and fragments in agricultural lands?

3. Does the condition of remnants compared with larger conservation parks influence the distribution of reptiles?

4. To what extent are reptile species able to use the matrix?

\section{METHODS}

The study was conducted on the Eyre Peninsula, South Australia on the north-west corner of Hambidge Conservation Park and on adjacent farmland (Fig. 1). The mean annual rainfall for the area is $316 \mathrm{~mm}$, with rainfall predominantly in winter. The farmland in 


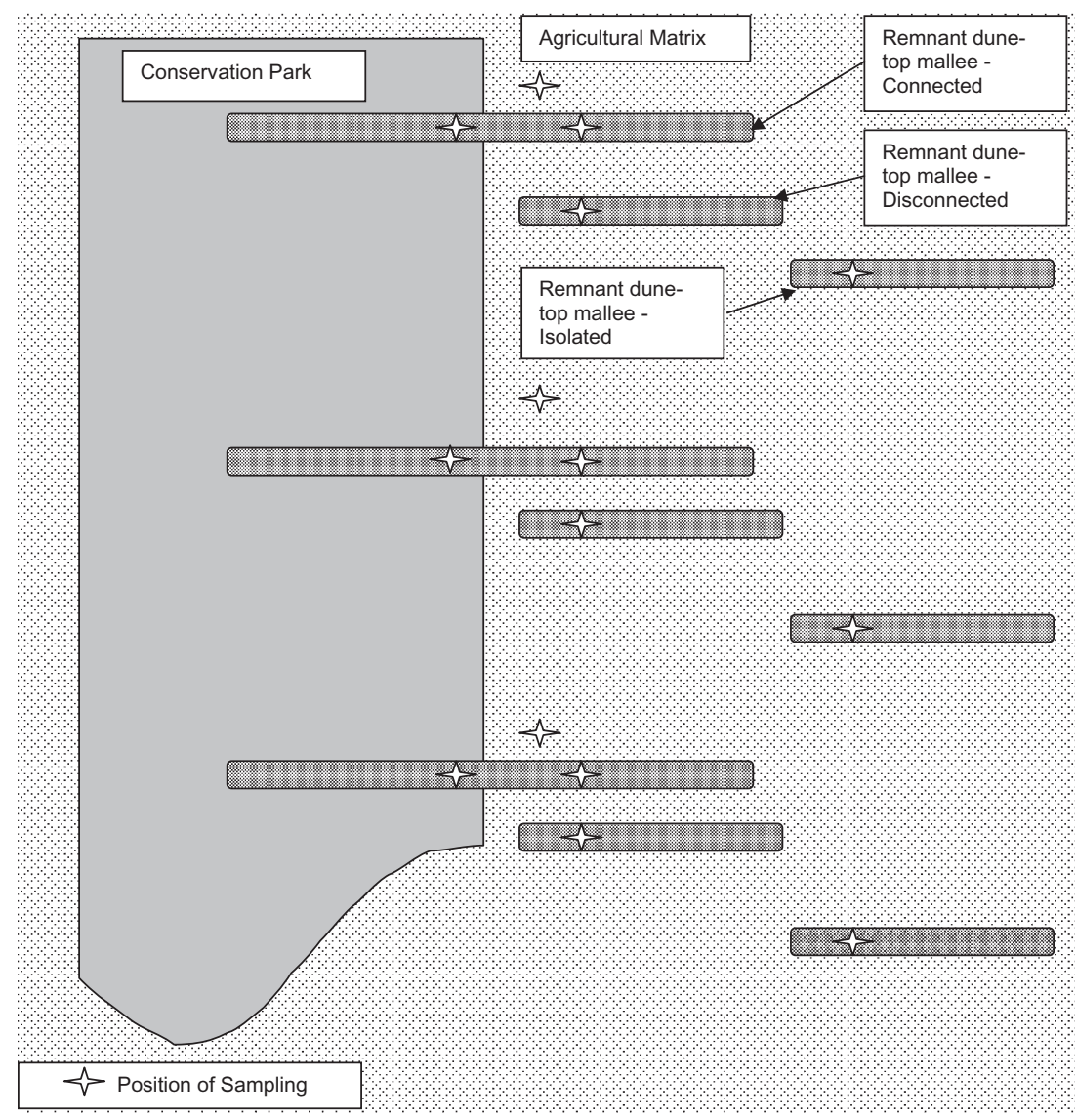

Fig. 2. The survey design shows three sets (replicates) of the five landscape elements: the Conservation Park, connected, disconnected, isolated and the matrix. All the dune-top vegetation has similar clearing and grazing history.

which the study was conducted is primarily used for sheep and cereal farming. Hambidge Conservation Park and adjacent remnants consist mostly of mallee vegetation dominated by Eucalyptus socialis and Eucalyptus incrassata, with only a small proportion of woodlands and shrublands. The soils of the Conservation Park include parallel dunes of silicious sands (DEH 2005). The deep sands offer poor soils for cropping and so most of the dune-tops in this region remain uncleared. The landscape is therefore permeated by many long, thin, parallel remnants.

Sampling was conducted in three replicate locations: Kelly's, Dolphin's and Sampson's, each being a separate farm property. All three properties were located within a distance of $10 \mathrm{~km}$, with the properties being located on the western and north-western corners of Hambidge Conservation Park. At each location, sampling was conducted in five landscape elements: the Conservation Park, a fragment connected to the Conservation Park, a disconnected fragment $(50-100 \mathrm{~m}$ from the Conservation Park), isolated fragments (1500-2800 $\mathrm{m}$ from the Conservation Park) and the matrix (Fig. 2).
Sampling at each site was conducted using a transect of ten 21-litre pitfall traps spaced at 25-m intervals and each with $10 \mathrm{~m}$ of $30-\mathrm{cm}$ high black plastic drift fence. In the Conservation Park, transects began $10 \mathrm{~m}$ from the edge of the park, with the transect running along the dune-top. To avoid confounding distance from the Conservation Park with isolation, transects in the connected and disconnected remnants were placed at equal distances from the Conservation Park. In the disconnected and isolated fragments, transects were placed $70 \mathrm{~m}$ from the end of the fragment nearest to the Conservation Park. The position of the matrix samples was constrained to sites that would not disrupt farming activities. The matrix transect on Kelly's was $100 \mathrm{~m}$ from the Conservation Park on a sandy dune-top and $200 \mathrm{~m}$ from remnant native vegetation and was the only matrix site on soils comparable to the remnants and the Conservation Park. The matrix transect on Dolphin's was positioned $100 \mathrm{~m}$ from the Conservation Park, on a ridge of rocky-clay type soils and the nearest vegetation was an adjacent sand-dune fragment $50 \mathrm{~m}$ away. The matrix transect on Sampson's was approximately $1286 \mathrm{~m}$ from the 
Conservation Park, in a compact clay depression. The transect ran adjacent to a revegetation site consisting almost entirely of small shrubs $(0.5 \mathrm{~m})$ and spinifex. The nearest mature vegetation was a dune-top remnant $130 \mathrm{~m}$ away. The matrix in all locations was used for both cropping and grazing and therefore consisted of a cover of annual grasses generally no more than $5 \mathrm{~cm}$ high. However, the matrix site in Sampson's, being in a compact clay depression, had very little vegetation cover and was mostly bare ground.

The pitfall traps had a damp sponge on the bottom, which was rehydrated daily, a small half piece of poly piping $50 \mathrm{~mm}$ in diameter and a piece of wood placed on top. These items provide shelter and moisture for the captured animals and a platform in the event of the buckets flooding. When ants were found in the vicinity of the buckets, insecticide spray was applied to the bucket rim to protect trapped animals. Reptile taxonomy follows Wilson and Swan (2003), except for Pogona sp. which appear to be a single taxon in our study sites (Jane Melville, pers. comm., 2006).

Reptiles were sampled on five separate trips over the period of November 2005 to January 2006. The traps were opened for five, six or seven nights consecutively per trip for a total of 30 nights of sampling. Once the traps were opened they remained opened constantly for the period of sampling and were checked daily in the early morning. Reptiles were marked by toe clipping. Recaptured animals were not included in calculations of abundance and all recaptures were from within the same site; therefore, no movement between landscape elements was detected. The reptiles were released the day after capture, within $10-20 \mathrm{~m}$ of the capture site.

A vegetation survey was conducted for each site using five $10 \times 10 \mathrm{~m}$ quadrats, which were placed between every second pair of pitfall traps. The quadrats were placed alternately $5 \mathrm{~m}$ to each side of the top of the dune. Within each of the quadrats we recorded the presence of plant species and an estimate of the percentage cover of bare ground, spinifex and leaf litter.

\section{Analysis}

The reptile data were pooled across traps and times within site. Analyses were performed using Generalized Linear Models (GLMs), assuming a Poisson distribution of the count data with a natural logarithm link function (McCullagh \& Nelder 1989; Nicholls 1989). Using a Poisson model we expected a residual mean deviance of one (McCullagh \& Nelder 1989). However, a value greater than one was often observed, indicating over-dispersion. To take over-dispersion into account, the mean deviance/residual mean deviance was used in an $F$-test.
We first tested for differences between the matrix sites and the vegetated sites after fitting location. The matrix communities were so different from the vegetated landscape elements, that it would obscure other less obvious trends if matrix was included in subsequent analyses. For the main analyses we fitted location first, then landscape element (the Conservation Park, connected, disconnected, isolated) for the following groups: total reptile abundance, reptile species richness, skink and snake abundance and the abundance for the 10 most common species (Nephrurus stellatus, Ctenotus atlas, Hemiergis millewae, Lerista distinguenda, Lerista terdigitata, Lerista edwardsae, Menetia greyii, Aprasia inaurita, Ramphotyphlops australis, Ramphotyphlops bituberculatus). The species chosen for analysis were those with captures at least equal to the number of sites used in the analysis (Didham et al. 1998).

The same GLM model was used to analyse the plant data. The effect of landscape elements (the Conservation Park, connected, disconnected and isolated) was tested for plant species richness, trees $(>4 \mathrm{~m})$, tall shrubs $(1.5-4 \mathrm{~m})$, small shrubs $(<1.5 \mathrm{~m})$ and grass/ sedge/herb species richness, as well as percent cover of bare ground, leaf litter and spinifex. Data for each species were pooled across quadrats to record site-level presence/absence allowing counts of species in each category to be made.

To test for possible edge effects, GLMs with Poisson distribution and logarithm link function were conducted on reptile data from the Conservation Park only. The analysis assumed each pitfall trap was an independent sample. The GLM fitted location first, and then the distance of the pitfall traps second. This was conducted on both reptile abundance and species richness to determine if there was an effect of distance from the Conservation Park edge on the reptile community.

A stepwise analysis using a GLM with Poisson distribution and a logarithm link was used to determine if any of the environmental or biogeographical variables were correlated with the distribution of reptiles ( $R$ Core Development Team 2004). Two measures of spatial configuration of the sites were made using aerial photographs: distance of fragments to the Conservation Park and the width of the fragments. The width of the fragment of the Conservation Park was given as the width equal to the largest fragment; therefore, all the variation in fragment width was contained within the farmland fragments. This forced the analysis to compare the fragment widths in the farmland and prevented the Conservation Parks from having an overwhelming influence. Isolation distance was given as the shortest distance of matrix between the Conservation Park and the fragments if using other fragments as stepping stones. Therefore, the Conservation Park and connected site received a value of zero. The 
environmental factors included plant species richness and percent cover of bare ground, leaf litter and spinifex, the latter three averaged across the five quadrats within each site. The stepwise analysis was conducted on total reptile abundance, reptile species richness, abundance of skinks, snakes, Lerista spp. and the 10 most common species defined previously. Geckos were not analysed as a group in this study because they consisted almost entirely of $N$. stellatus (100 of 103 captures).

Multidimensional Scaling (MDS) based on a BrayCurtis distance matrix was used to examine the overall dissimilarity of the reptile and plant community between vegetated landscape elements. The plant presence/absence data were summed across the five quadrats, providing a ranking of zero to five for each species at each site. MDS was completed using functions initMDS and isoMDS of $\mathrm{R}$ version 2.0.1 ( $\mathrm{R}$ Core Development Team 2004). Multiple starts were undertaken to avoid being trapped in local minima and new starts were continued until the stress had not been reduced for 100 successive iterations. The maximum number of iterations within isoMDS was 200, and convergence tolerance $10^{-7}$. The resulting ordination was rotated using post-MDS so that most of the variation was captured in axis 1 ( $\mathrm{R}$ Core Development Team 2004). To test for significant differences among landscape elements for both the reptile and vegetation community, an Analysis of Similarity (ANOSIM; Clarke 1993) was used on the pairwise distance matrix. The ANOSIM was conducted first with all the landscape elements (park, connected, disconnected and isolated) remaining separate and then with only two categories, farmland (connected, disconnected and isolated) and Conservation Park.

A power analysis was used to determine the minimum detectable contrast needed to achieve reasonable power in our GLMs testing for landscape element effects with reptiles. The minimum detectable contrast is the actual size of differences between treatment means that would be needed to achieve a particular power for a specified alpha. We compare the minimum detectable contrast with the overall mean abundance of reptile taxa as a guide to how likely we were to detect actual differences. With alpha set at 0.05 , and power at 0.8 , the minimum detectable contrast was calculated based on the experimental design and the standard deviation for each group, which was derived from the residual deviance of the GLM (Lenth 2006).

\section{RESULTS}

\section{Reptiles}

We captured 473 reptiles, of which 44 were recaptures. There were 22 species, of which five were common
(>30 captures), six were uncommon (10-30 captures) and 11 were rare ( $<10$ captures) (Table 1$)$.

The reptile community in the matrix was very different to the community in the vegetated landscape elements for both reptile abundance $\left(F_{1,11}=22.92\right.$; $P=0.0006$, mean vegetated landscape elements 35.2 (95\% CI 36.6-37.7), mean matrix 2.3 (0.7-7.9)), and species richness $\left(F_{1,11}=36.55 ; P=0.00008\right.$, mean vegetated 9.9 (9.4-10.4), mean matrix 2 (1.2-3.2)). Only seven reptiles were captured in the matrix (Table 1).

Comparing the four vegetated landscape elements, there were no significant differences. This was evident with both reptile abundance and species richness $\left(F_{3,6}=1.10, \quad P=0.42\right.$ and $F_{3,6}=0.29, \quad P=0.83$, respectively). There was no trend evident for species richness, but there was a trend towards fewer animals being captured in the Conservation Park, and connected remnants. Furthermore, the 10 most common species and two reptile families also showed no significant difference in abundance in the different landscape elements ( $N$. stellatus $\left(F_{3,6}=0.83, P=0.52\right), C$. atlas $\left(F_{3,6}=3.03, \quad P=0.12\right), \quad H$. millewae $\quad\left(F_{3,6}=2.19\right.$, $P=0.19), \quad L$. distinguenda $\left(F_{3,6}=0.84, \quad P=0.52\right)$, L. terdigitata $\left(F_{3,6}=0.23, \quad P=0.87\right), \quad L$. edwardsae $\left(F_{3,6}=0.51, \quad P=0.69\right), \quad M$. greyii $\quad\left(F_{3,6}=0.98\right.$, $P=0.46), \quad A$. inaurita $\quad\left(F_{3,6}=0.32, \quad P=0.81\right)$, $R$. australis $\left(F_{3,6}=0.81, P=0.53\right), R$. bituberculatus $\left(F_{3,6}=2.10, P=0.20\right)$, skinks $\left(F_{3,6}=0.59, P=0.65\right)$ and snakes $\left.\left(F_{3,6}=0.50, P=0.69\right)\right)$. Finally, the MDS confirmed the lack of differentiation between the reptiles in the different landscape elements (stress = 13.1 and ANOSIM $P=0.19$, Fig. 3).

While there were no significant effects of landscape element for any of the reptile taxa, both $H$. millewae and $R$. bituberculatus were recorded in every landscape element in the agricultural lands including the matrix. However, they were not recorded in the Conservation Park. In contrast, four out of five species that were only captured once were captured in Conservation Parks. If these five rare species had an equal chance of being trapped on any site, the probability of capturing four rare species in the three Conservation Park sites and one in the nine remnant sites is 0.015 .

There appeared to be no effect of the edge environment on the reptile community. The distance that a pitfall trap was located from the edge of the Conservation Park had no influence on either the abundance or species richness of reptiles caught in that pitfall trap $\left(F_{9,18}=0.53, \quad P=0.84\right.$ and $F_{9,18}=0.46, \quad P=0.89$, respectively). Furthermore, the species in the Conservation Park recorded with only one capture appeared to show no tendency to avoid the edge with the four species being caught in second, third, sixth and ninth pitfall trap from the edge. In addition, there were no strong trends among the more common species; for the seven species with more than three records in the 
Table 1. Reptile captures for each species and the total for each landscape element

\begin{tabular}{|c|c|c|c|c|c|c|}
\hline & Taxon & Isolated & Disconnected & Connected & Park & Matrix \\
\hline Pogona sp. & $\mathrm{D}$ & 3 & 2 & 3 & 2 & 1 \\
\hline Brachyurophis semifasciatus & $\mathrm{E}$ & 0 & 1 & 1 & 5 & 1 \\
\hline Demansia psammophis & $\mathrm{E}$ & 1 & 1 & 0 & 0 & 0 \\
\hline Simoselaps bertholdi & $\mathrm{E}$ & 0 & 0 & 0 & 1 & 0 \\
\hline Diplodactylus damaeus & $\mathrm{G}$ & 0 & 1 & 0 & 0 & 0 \\
\hline Diplodactylus granariensis & G & 0 & 0 & 0 & 1 & 0 \\
\hline Nephrurus stellatus & G & 28 & 33 & 21 & 18 & 0 \\
\hline Strophurus assimilis & G & 0 & 0 & 0 & 1 & 0 \\
\hline Aprasia inaurita & $\mathrm{P}$ & 4 & 4 & 3 & 2 & 0 \\
\hline Delma butleri & $\mathrm{P}$ & 0 & 2 & 1 & 0 & 0 \\
\hline Pygopus nigriceps & $\mathrm{P}$ & 0 & 1 & 0 & 1 & 0 \\
\hline Ramphotyphlops australis & $\mathrm{R}$ & 5 & 6 & 4 & 1 & 0 \\
\hline Ramphotyphlops bituberculatus & $\mathrm{R}$ & 10 & 3 & 4 & 0 & 2 \\
\hline Ctenotus atlas & $\mathrm{S}$ & 8 & 28 & 17 & 4 & 0 \\
\hline Cyclodomorphus melanops & S & 1 & 1 & 0 & 0 & 0 \\
\hline Hemiergis millewae & $S$ & 10 & 6 & 4 & 0 & 1 \\
\hline Lerista distinguenda & $\mathrm{S}$ & 6 & 16 & 11 & 8 & 0 \\
\hline Lerista edwardsae & S & 22 & 9 & 10 & 14 & 0 \\
\hline Lerista terdigitata & $S$ & 13 & 5 & 5 & 7 & 0 \\
\hline Menetia greyii & $S$ & 13 & 9 & 10 & 5 & 2 \\
\hline Morethia obscura & S & 0 & 0 & 0 & 1 & 0 \\
\hline Tiliqua rugosa & $\mathrm{S}$ & 3 & 1 & 1 & 0 & 0 \\
\hline Total number of species & & 14 & 18 & 14 & 15 & 5 \\
\hline Total number of individuals & & 127 & 129 & 95 & 71 & 7 \\
\hline
\end{tabular}

Recaptures were not included. Taxon indicates family: D, dragons (Agamidae); E, venomous snakes (Elapidae); G, Geckos (Geckonidae); P, legless lizards (Pygopodidae); R, blind snakes (Ramphotyphlopidae); S, skinks (Skinkidae).

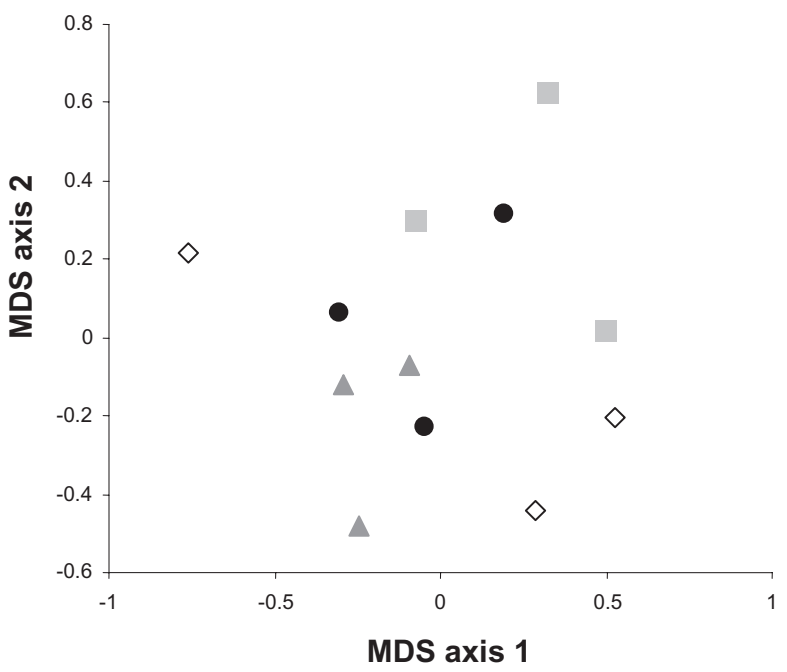

Fig. 3. Non-metric Multidimensional Scaling of reptile communities for three sites of each of five landscape elements (diamonds $=$ isolated, triangles $=$ disconnected, circles $=$ connected, squares $=$ Conservation Park).

Conservation Parks, all had records from both the first $50 \mathrm{~m}$ and $50-100 \mathrm{~m}$ from the edge.

Only four of the reptile taxa analysed had minimum detectable contrast less than their mean abundance. The other 10 groups had minimum detectable con-
Table 2. The minimum detectible contrast compared with the mean abundance of reptile taxa, where alpha was set at 0.05 and power at 0.8

\begin{tabular}{lcc}
\hline Taxon & $\begin{array}{c}\text { Mean } \\
\text { abundance }\end{array}$ & $\begin{array}{c}\text { Minimum } \\
\text { detectable } \\
\text { contrast }\end{array}$ \\
\hline Total reptiles & 53.17 & 11 \\
Reptile species richness & 9.92 & 4 \\
Skinks & 20.67 & 13 \\
Snakes & 3.58 & 7 \\
Aprasia inaurita & 1.08 & 5 \\
Ctenotus atlas & 4.75 & 7 \\
Hemiergis millewae & 1.67 & 7 \\
Lerista distinguenda & 3.42 & 7 \\
Lerista edwardsae & 4.58 & 9 \\
Lerista terdigitata & 2.50 & 12 \\
Menetia greyii & 3.08 & 5 \\
Nephrurus stellatus & 8.33 & 7 \\
Ramphotyphlops australis & 1.33 & 6 \\
Ramphotyphlops bituberculatus & 1.42 & 7 \\
\hline
\end{tabular}

trast one to five times greater than the mean abundance (Table 2), indicating that only very large differences between treatments were likely to be detected. For example, L. terdigitata had a mean abundance of 2.5, with a minimum detectible contrast of 12 (Table 2). Therefore, a landscape element would require an abundance of $L$. terdigitata approximately

Journal compilation (C) 2008 Ecological Society of Australia 
five times greater than the mean for all the other landscape elements for a significant difference to have an $80 \%$ chance of detection.

\section{Vegetation}

Forty-nine plant species were recorded across the 12 sites. Of those, 11 could not be identified because of lack of flowers and indistinct vegetative parts, but they were identified as morphospecies.

Plant species richness was significantly different in the Conservation Park relative to the fragments in the agricultural land $\left(F_{3,6}=5.70, P=0.034\right)$ with the Conservation Park having higher species richness (Fig. 4A). This result appeared largely due to the shrub species. Tall shrubs had a significantly higher species richness in the Conservation Park $\left(F_{3,6}=\right.$ 10.51, $P=0.0084$, Fig. 4B) and small shrubs, while not significant, had a strong trend towards increased diversity in the Conservation Park $\left(F_{3,6}=3.94, P=\right.$ 0.072 , Fig. $4 \mathrm{C}$ ). However, there was no significant difference for trees $\left(F_{3,6}=0.50, P=0.70\right)$ and grasses/ sedges/herbs $\left(F_{3,6}=0.31, P=0.81\right)$. For the analysis of ground cover, there was also no effect of landscape element for any of the categories, bare ground $\left(F_{3,6}=0.1602, P=0.9193\right)$, leaf litter $\left(F_{3,6}=0.34\right.$, $P=0.79)$ or spinifex $\left(F_{3,6}=0.12, P=0.94\right)$.

The difference in plant species composition between the Conservation Park and the farmland fragments was further supported with the MDS. The sites were classified as being either park or farmland. The plot showed a clear distinction between the two categories (stress $9.5 \%$, Fig. 5) with the ANOSIM demonstrating a significant effect $(P=0.001)$. An ANOSIM comparing the four landscape elements parks, connected, disconnected and isolated was not significant $(P=0.30)$, suggesting that the sites in farmland had similar vegetation, regardless of connectivity.

\section{Correlation of plant and biogeographical variables with reptile community}

Among site variables, only bare ground was found to be associated with any aspect of the reptile community. The total reptile abundance was found to have a weak positive correlation with bare ground $\left(F_{1,10}=3.81\right.$, $P=0.079$ ), which accounted for more than a quarter of the variation (deviance 21.04 of total deviance 76.21, Fig. 6). However, the Cook's distance plot (Crawley 2002) showed that the Conservation Park site at Dolphin and the isolated site in Kelly had a very large effect on the result relative to the other sites. When these sites were removed, the positive association of bare ground with reptile abundance was

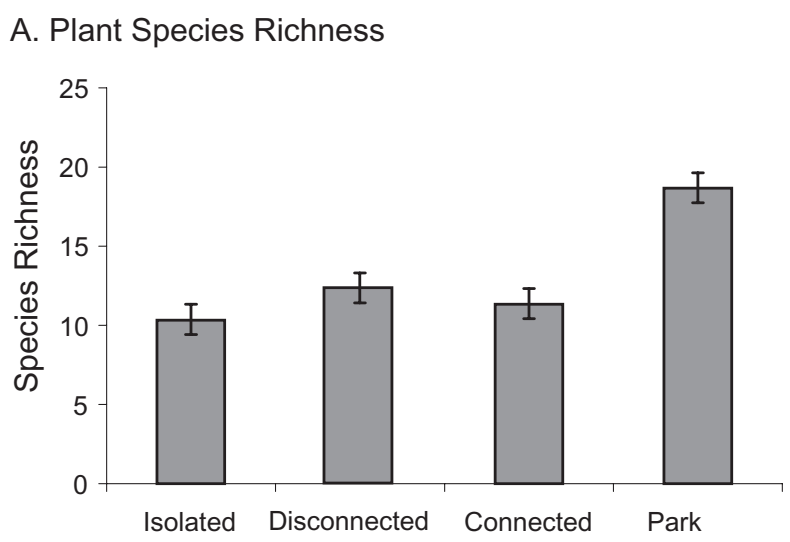

B. Tall Shrub Species Richness

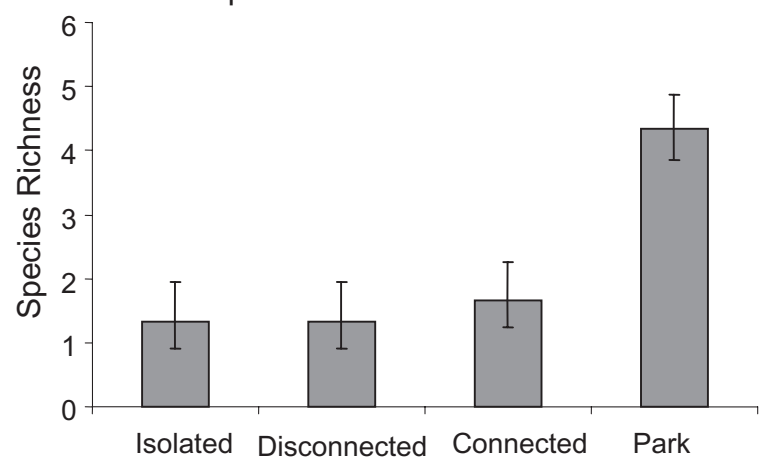

C. Small Shrub Species Richness

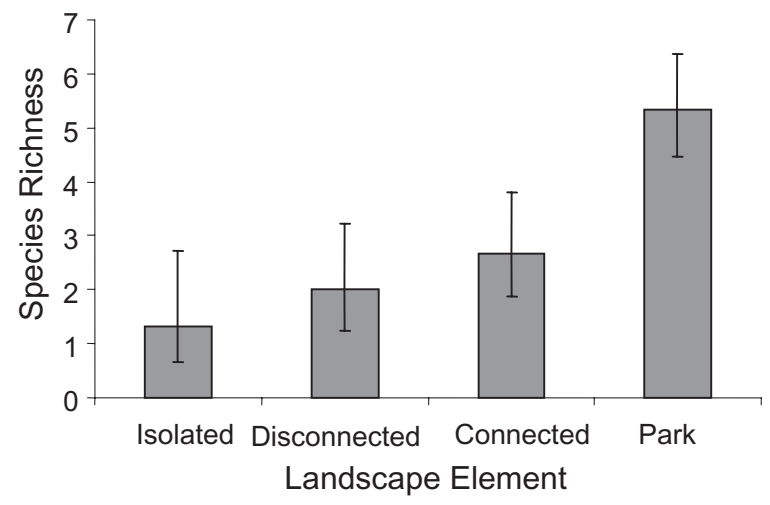

Fig. 4. Plant species richness (A), species richness of tall shrubs (B) and species richness of small shrubs (C). Error bars indicate $95 \%$ confidence intervals.

significant $\left(F_{1,8}=6.52, P=0.034\right)$ explaining nearly half of the overall variation in total reptile abundance (16.16 of 35.99 deviance).

The only species to show any association with site variables was the skink $H$. millewae which had a significant positive correlation with bare ground $\left(F_{1,10}=6.74, P=0.027\right)$ that explained a third of the variation in abundance (deviance 12.98 of total deviance 32.25) (Fig. 7). The Conservation Park site in Dolphin had a strong influence on the relationship with bare ground according to the Cook's distance 


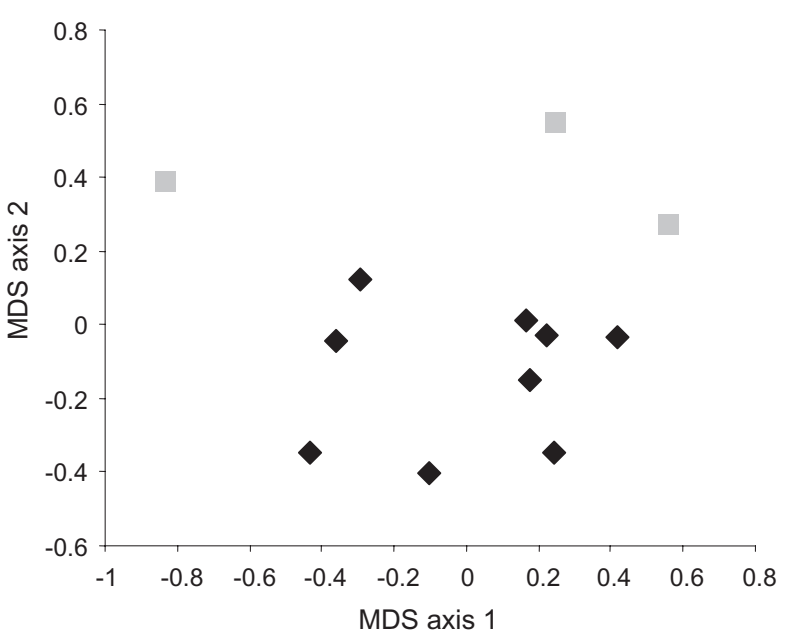

Fig. 5. Non-metric Multidimensional Scaling of the plant community in the farmlands (black diamonds) and the conservation park (grey squares).

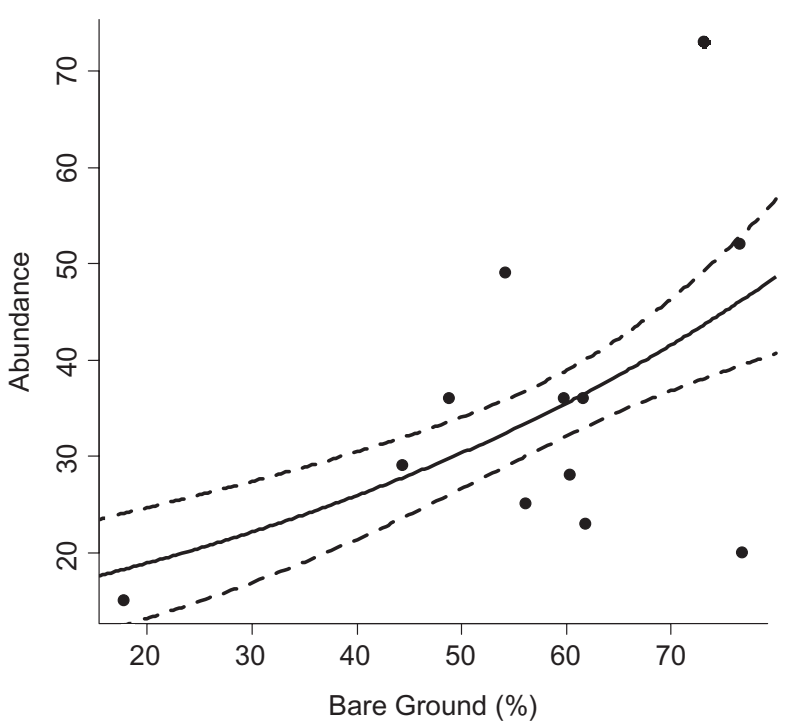

Fig. 6. Relationship between total reptile abundance and percentage cover of bare ground. Regression lines and 95\% confidence bands indicated.

plot; however, with this removed the correlation became even stronger $(P=0.00001)$. To determine if $H$. millewae was the significant factor in creating the positive trend in total reptile abundance with bare ground, the analysis on total reptiles was conducted a second time with $H$. millewae data removed. While the association became slightly weaker, there still existed a low positive trend $\left(F_{1,10}=3.19, P=0.10\right)$.

The only biogeographical factor significantly correlated with any aspects of the reptile community was fragment width. Fragment width had a significant negative association with snake abundance $\left(F_{1,10}\right.$

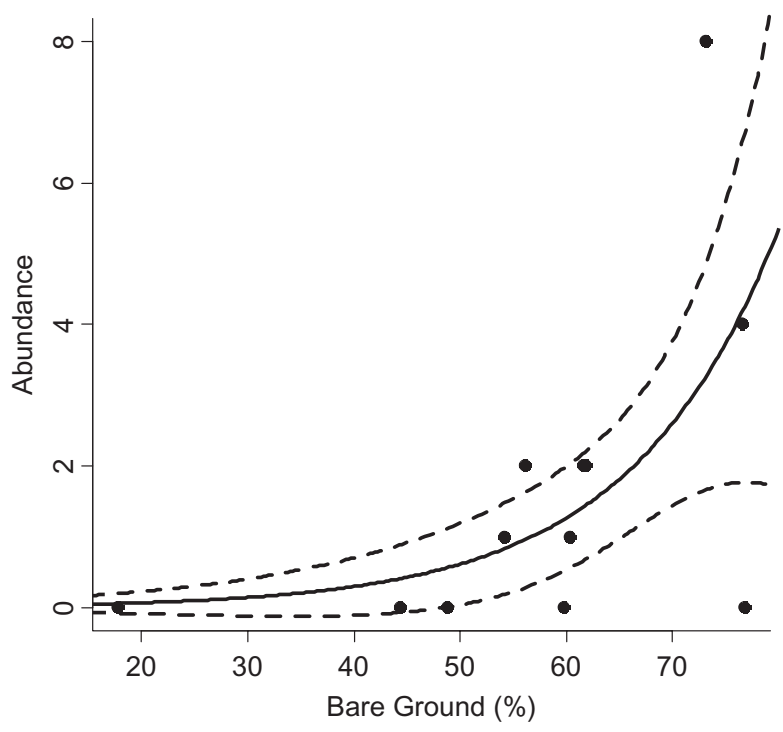

Fig. 7. Relationship between Hemiergis millewae abundance and percentage cover of bare ground. Regression lines and $95 \%$ confidence bands indicated.

17. $65, P=0.00003)$. However, this result was not significant when the blind snake, $R$. bituberculatus, was excluded from the data set. The significant association of $R$. bituberculatus with width $\left(F_{1,10}=37.52, P=\right.$ $0.0001)$ explained over three quarters of the variation (deviance 27.08 of total deviance 34.30). The isolated site in Kelly had a very strong effect on the results, but with that site removed there remained a significant association $\left(F_{1,9}=7.27, P=0.025\right)$ (Fig. 8$)$.

\section{DISCUSSION}

The spatial configuration of the fragments in the agricultural landscape had no detectable influence on the reptile community composition. The absence of an isolation effect could arise if the reptiles were stranded on the fragments at the time of clearing and have managed to survive so far but with time will become extinct (Sarre et al. 1995; Driscoll \& Hardy 2005). This is not supported by the clearing history however, because Kelly's property was cleared between 1963 and 1977, Dolphin's between 1968 and 1970 and Sampson's between 1982 and 1985. However, the most recently cleared site (Sampson's) had the lowest abundance of reptiles, while all properties had similar species richness. This is opposite to what would be expected if the populations were isolated and going extinct over time.

An alternative explanation is that some reptile species are able to disperse between fragments. Increased dispersal ability can counteract the effects of fragmentation (With \& Crist 1995; Bender et al. 1998; 


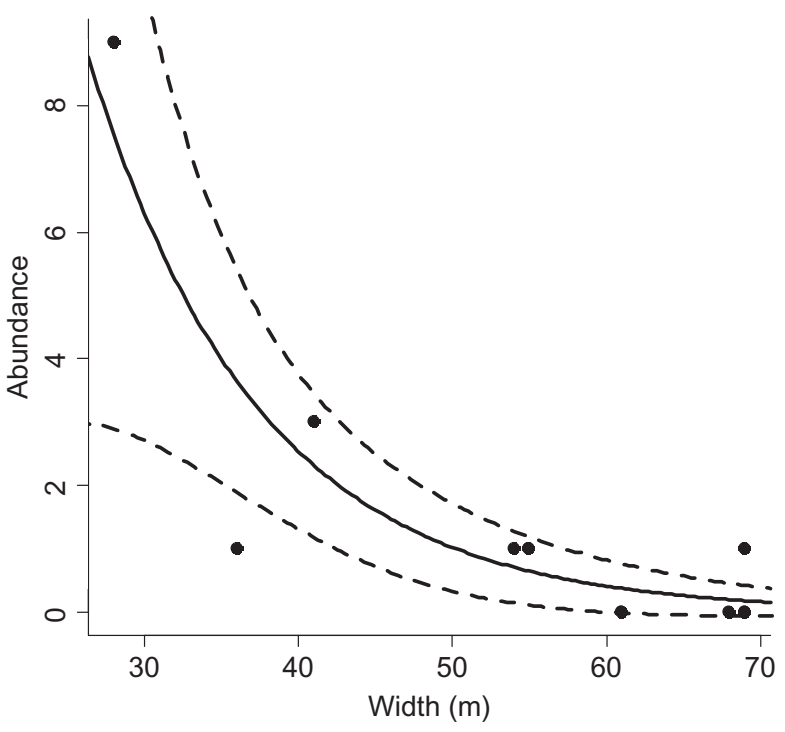

Fig. 8. Relationship between blind snake Ramphotyphlops bituberculatus abundance and width $(\mathrm{m})$ of the fragments. Regression lines and 95\% confidence bands indicated.

Driscoll \& Weir 2005). For some species there was direct evidence of movement into the matrix. Seven individuals of five different species were captured in the matrix (M. greyii, H. millewae, R. bituberculatus, Brachyurophis semifasciatus and Pogona sp.). However, five of the seven captures were in the dune-top matrix site in Kelly's which was $100 \mathrm{~m}$ from any native vegetation. There were only two animals captured in our matrix sites that were not on sand-dunes, even though they were a similar or shorter distance from remnant vegetation. Movement between parallel dunes through cleared swale habitat may be more restricted than movement along dunes. These results are consistent with Driscoll's (2004) observation that only two individual reptiles (both $R$. bituberculatus) were captured in the matrix, where sites were more than $500 \mathrm{~m}$ from remnant vegetation and there was no dune structure. Therefore, there is very little evidence for dispersal between dunes. On current evidence we cannot distinguish between either a very slow rate of local extinction in isolated remnants or occasional migration across the matrix, either of which could be producing the lack of isolation effects. To decide between these alternatives, tracking individual animals across the landscape or genetic analysis is needed.

The low power of most analyses urge caution in assuming there is no isolation effect. Some species, particularly the species captured less often, may have an isolation effect that was not detected. However, the general absence of non-significant trends in addition to the absence of significant effects suggests that our overall conclusion that there is no isolation effect among the common species is reasonable.
There may be other reptile species that were affected by fragmentation in the agricultural lands that were not identified in this study. Reptiles can be highly specialized, with different species found most commonly on dune-tops, dune-bases or in the swales between dunes (Pianka 1996). Because all the sampling was conducted on dune-tops in this study, swale specialists would be either under represented or completely absent from the data. This is of particular importance because it is the swales that have been cleared from the agricultural lands and so it is the swale specialists that are most likely to be affected. Specialization to use swale habitat might explain why there were more species with only a single record in the Conservation Parks. The habitat specialization of most species in this study is unknown. However, we speculate that the absence of four species from dune-top remnants but their presence in the Conservation Park may reflect specialization to use the swale or dunebases, habitats that have been cleared in the farming landscapes.

While not significant, $H$. millewae and $R$. bituberculatus were both caught at every level of isolation and in the matrix; however, neither was recorded in the Conservation Park. H. millewae showed a positive correlation with the percentage cover of bare ground. These two species appear to prefer the disturbed remnants in farmland, a result that is consistent with other studies showing higher reptile abundance in open grazed or recently burnt sites (Caughley 1985; Masters 1996; Fabricius et al. 2003; Driscoll and Henderson 2007).

The test for an edge effect was aimed at identifying species that avoid edge habitat and therefore would be unlikely to move out into the fragments regardless of the condition or connectivity of the fragments (Bender et al. 1998; Anderson \& Burgin 2002; Harper et al. 2005). Although low capture numbers made it difficult to detect an edge effect if there was one, we found no evidence supporting a strong edge effect. If correct, this may be a valuable observation because it means that even small linear remnants have the potential to function as reptile habitat for the common species in the landscape.

Of the biogeographical factors examined, only fragment width had a negative association with the blind-snake $R$. bituberculatus. The relationship of $R$. bituberculatus abundance with fragment width was surprising because fragment width is a surrogate for area, with the length of the disconnected and isolated fragments being roughly the same. Therefore, $R$. bituberculatus abundance was negatively correlated with fragment size, potentially contesting fragmentation theory, which predicts increasing diversity and abundance with increasing area (MacNally \& Horrocks 2002; Ferraz et al. 2003; Krauss et al. 2003). However, pit-trap efficiency and snake movement presents a likely 
explanation. If snakes are moving parallel with the edge of the remnant, they are more likely to be captured in a narrow remnant because the 10-m drift fence will block a higher proportion of the width of the remnant. Consequently, the increase in sampled snake abundance in narrower strips could represent an increase in capture rates rather than an actual increase in abundance. This is similar to a finding by Driscoll (2004) where the snake Suta nigriceps was captured more often in linear strips than the reserves. Mark-recapture or radiotelemetry data are needed to test this hypothesis.

It is possible that constrained movement in the dune-tops has also influenced the capture rate of $H$. millewae in linear remnants compared with the Conservation Park. If constrained linear movement is a common process and most species are more likely to be captured in the linear fragments, then a greater proportion of recaptures should have been in the fragments compared with the Conservation Park. However, this was not the case, with $10.3 \%$ of original captures being recaptured in the paddock fragments, compared with $12.7 \%$ in the Conservation Park. This suggests that parallel movement along dunes is generally similar in fragments and continuous mallee.

Trapability may also be influenced by different vegetation structure in grazed and ungrazed habitats (Bromham et al. 1999; Yates et al. 2000; Landsberg et al. 2003). However, Schlesinger (1999) found that reptile capture rates in pitfall traps were not significantly different in grazed and ungrazed sites in central Australia. Therefore, the structural differences in vegetation in the different landscape elements may not have an over-riding influence on trapability and the differences in capture rates may reflect real population differences. This is a widespread assumption that underlies nearly every vertebrate pit-fall trapping study, and it needs further examination.

Although fragmentation including increased patch isolation can be detrimental to plant populations (Lienert et al. 2002), in this study the fragments in the farmland had similar levels of species richness despite contrasting isolation. However, significantly higher plant species richness in the Conservation Park compared with remnants is most likely the result of direct impacts of agricultural processes on remnants. The reduction of shrub species richness probably reflects the impact of live-stock grazing. Smith et al. (1996) found that grazing was associated with reduction or elimination of understorey shrub cover, while Yates et al. (2000) also found lower perennial shrub cover in grazed compared with ungrazed sites. Bromham et al. (1999) recorded a complete removal of the understorey in grazed sites. However, other possible causes such as the effects of herbicide drift or increased nutrient levels from the agricultural land could also be contributing factors to the altered plant species composition (Boutin \& Jobin 1998).

\section{CONCLUSION}

The reptile community appeared to be largely unaffected by the spatial configuration of the fragments. The level of isolation seemingly had no effect on either reptile abundance, species richness or abundance of common species. Unexpectedly, the reptile community was also largely unaffected by the impact of agricultural practices on the fragments, including grazing and the use of adjacent land for the production of crops (Boutin \& Jobin 1998; Read 2002; Landsberg et al. 2003). Decreasing plant species richness and altered plant structure in the farmland fragments appeared not to affect the reptile community, with the exception of $H$. millewae, which increased. To an extent this finding contradicts other studies that have found that grazing had significant detrimental effects on reptile community composition (Fabricius et al. 2003; James 2003; Beever \& Brussard 2004; Driscoll 2004). For common reptile species, our data suggest that dune-top remnants permeating agricultural landscapes have the potential to provide connectivity, although estimates of dispersal ability need to be completed to distinguish isolation with slow extinction from dispersal between remnants.

Our data hinted at the existence of a suite of reptile species that may not be able to use the dune-top remnants and these may include species that specialize in using swales and dune-bases (Pianka 1996). These species were rare in our study, so we cannot exclude the possibility that they are affected by isolation in addition to habitat condition. More detailed sampling in swales in Conservation Parks and in linear remnants that cross swales (such as along roadsides) is needed. Our study only examined sites that were within a few kilometres of a large conservation park. An isolation effect may only be manifest at greater distances from the park where there is less overall habitat in the landscape (Fahrig 2003), so further examination of isolation effects is a priority.

We did observe a clear loss of plant diversity from the fragments in the agricultural landscape, associated with habitat condition not isolation. This is of conservation concern, because it could indicate a loss of plant species richness from the broader agricultural landscape. Furthermore, the loss of plant species richness may affect other taxonomic groups, such as invertebrates, birds and small mammals (Steffan-Dewenter \& Tscharntke 2002; James 2003; Martin \& Possingham 2005). A more detailed focus on plant distribution through the dune-top remnants is needed, and in the meantime, excluding stock from remnant vegetation is likely to assist plant species recovery.

Our study indicates that the dune-top remnants have an important role in maintaining reptile diversity in farming lands. Regardless of if they currently allow dispersal across the landscape, the remnants have 
enormous potential to help facilitate the large-scale connectivity envisaged in projects such as WildCountry (Recher 2003).

\section{ACKNOWLEDGEMENTS}

Thanks to the landholders Ian Kelly, Darryl Dolphin and Craig Sampson for access to sites and assistance in the field. The accommodation provided by Peter Hitchcock was greatly appreciated. Brooke Swaffer's plant expertise enabled completion of the vegetation surveys. Brooke Swaffer, Julie Schutz and Madelaine Hanson participated as field assistants. Rosie Roberts and Tom Cole reviewed the grammar of Adam's honours thesis work. The Department for Environment and Heritage of South Australia provided funding and Paula Peeters' support from DEH Port Lincoln was appreciated. This project was completed under ethics permit E197 from Flinders University, and under Department For Environment and Heritage permit U24990.

\section{REFERENCES}

Anderson L. \& Burgin S. (2002) Influence of woodland remnant edges on small skinks (Richmond, New South Wales). Aust. Ecol. 27, 630-7.

Beever E. A. \& Brussard P. F. (2004) Community- and landscape-level responses of reptiles and small mammals to feral-horse grazing in the Great Basin. F. Arid Environ. 59, 271-97.

Bender D. J., Contreras T. A. \& Fahrig L. (1998) Habitat loss and population decline: a meta-analysis of the patch size effect. Ecology 79, 517-33.

Berry O., Tocher M. D., Gleeson D. M. \& Sarre S. D. (2005) Effect of vegetation matrix on animal dispersal: genetic evidence from a study of endangered skinks. Conserv. Biol. 19, $855-64$

Borrvall C. \& Ebenman B. (2006) Early onset of secondary extinctions in ecological communities following the loss of top predators. Ecol. Lett. 9, 435-42.

Boutin C. \& Jobin B. (1998) Intensity of agricultural practices and effects on adjacent habitats. Ecol. Appl. 8, 544-57.

Bromham L., Cardillo M., Bennett A. F. \& Elgar M. A. (1999) Effects of stock grazing on the ground invertebrate fauna of woodland remnants. Aust. F. Ecol. 24, 199-207.

Caughley J. (1985) Effect of fire on the reptile fauna of mallee. In: Biology of Australasian Frogs and Reptiles (eds G. Grigg, R. Shine \& H. Ehmann) pp. 31-4. Royal Zoological Society of NSW and Surrey Beatty \& Sons, Chipping Norton.

Clarke K. R. (1993) Nonparametric multivariate analyses of changes in community structure. Aust. F. Ecol. 18, 11743.

Crawley M. J. (2002) Statistical Computing. An Introduction to Data Analysis Using S-Plus. Wiley, West Sussex.

Department for Environment and Heritage (DEH) (2004) NatureLinks. Implementing the Wildcountry Philosophy in South Australia. Department for Environment and Heritage, Government of South Australia, Adelaide.
Department for Environment and Heritage (DEH) (2005) Draft Management Plan, Mallee Parks of the Central Eyre Peninsula. Department for Environment and Heritage, Government of South Australia, Adelaide.

Didham R. K., Hammond P. M., Lawton J. H., Eggleton P. \& Stork N. E. (1998) Beetle species responses to tropical forest fragmentation. Ecol. Monogr. 68, 295-323.

Driscoll D. A. (2004) Extinction and outbreaks accompany fragmentation of a reptile community. Ecol. Appl. 14, 22040.

Driscoll D. A. (2005) Is the matrix a sea? Habitat specificity in a naturally fragmented landscape. Ecol. Entomol. 30, 8-16.

Driscoll D. A. \& Hardy C. M. (2005) Dispersal and phylogeography of the agamid lizard Amphibolurus nobbi in fragmented and continuous habitat. Mol. Ecol. 14, 1613-29.

Driscoll D. A. \& Weir T. (2005) Beetle responses to habitat fragmentation depend on ecological traits, remnant condition and shape. Conserv. Biol. 19, 182-94.

Driscoll D. A. \& Henderson M. K. (2007) How many reptile species are fire specialists? A replicated natural experiment to test fire succession models. Biol. Conserv DOI: 10.1016/ j.biocon.2007.10.016.

Ewers R. M. \& Didham R. K. (2006) Confounding factors in the detection of species responses to habitat fragmentation. Biol. Rev. 81, 117-42.

Fabricius C., Burger M. \& Hockey P. A. R. (2003) Comparing biodiversity between protected areas and adjacent rangeland in xeric succulent thicket, South Africa: arthropods and reptiles. F. Appl. Ecol. 40, 392-403.

Fahrig L. (2003) Effects of habitat fragmentation on biodiversity. Annu. Rev. Ecol. Evol Syst. 34, 487-515.

Ferraz G., Russell G. J., Stouffer P. C., Bierregaard R. O., Pimm S. L. \& Lovejoy T. E. (2003) Rates of species loss from Amazonian forest fragments. Proc. Natl. Acad. Sci. USA 100, 14069-73.

Fischer J., Fazey I., Briese R. \& Lindenmayer D. B. (2005) Making the matrix matter: challenges in Australian grazing landscapes. Biodivers. Conserv. 14, 561-78.

Harper K. A., Macdonald S. E., Burton P. J. et al. (2005) Edge influence on forest structure and composition in fragmented landscapes. Conserv. Biol. 19, 768-82.

Harrison S. \& Bruna E. (1999) Habitat fragmentation and largescale conservation: what do we know for sure? Ecography 22, 225-32.

Hartley S. E., Gardner S. M. \& Mitchell R. J. (2003) Indirect effects of grazing and nutrient addition on the hemipteran community of heather moorlands. F. Appl. Ecol. 40, 793-803.

Hobbs R. J. (2001) Synergisms among habitat fragmentation, livestock grazing, and biotic invasions in southwestern Australia. Conserv. Biol. 15, 1522-8.

James C. (2003) Response of vertebrates to fenceline contrasts in grazing intensity in semi-arid woodlands of eastern Australia. Aust. Ecol. 28, 137-51.

Jellinek S., Driscoll D. A. \& Kirkpatrick J. B. (2004) Environmental and vegetation variables have a greater influence than habitat fragmentation in structuring lizard communities in remnant urban bushland. Aust. Ecol. 29, 294-304.

Krauss J., Steffan-Dewenter I. \& Tscharntke T. (2003) How does landscape context contribute to effects of habitat fragmentation on diversity and population density of butterflies? F. Biogeogr. 30, 889-900.

Kupfer J. A., Malanson G. P. \& Franklin S. B. (2006) Not seeing the ocean for the islands: the mediating influence of matrixbased processes on forest fragmentation effects. Glob. Ecol. Biogeogr. 15, 8-20. 
Landsberg J., James C. D., Morton S. R., Muller W. J. \& Stol J. (2003) Abundance and composition of plant species along grazing gradients in Australian rangelands. F. Appl. Ecol. 40, 1008-24.

Lenth R. V. (2006) Fava Applets for Power and Sample Size. Division of Mathematical Sciences, Department of Statistics \& Actuarial Science, University of Iowa, Iowa. [Cited 9 August 2005.] Available from URL: http://www.stat.uiowa. edu/ rlenth/Power.html.

Levins R. (1970) Extinction. In: Some Mathematical Questions in Biology. Lectures on Mathematics in Life Sciences 2 (ed. M. Gerstenhaber) pp. 77-107. American Mathematical Society, Providence, RL.

Lienert J., Diemer M. \& Schmid B. (2002) Effects of habitat fragmentation on population structure and fitness components of the wetland specialist Swertia perennis L. (Gentianaceae). Basic Appl. Ecol. 3, 101-14.

McCoy E. D. \& Mushinsky H. R. (1994) Effects of fragmentation on the richness of vertebrates in the Florida scrub habitat. Ecology 75, 446-57.

McCullagh P. \& Nelder J. A. (1989) Generalized Linear Models, 2nd edn. Chapman \& Hall, London.

MacNally R. \& Horrocks G. (2002) Relative influences of patch, landscape and historical factors on birds in an Australian fragmented landscape. F. Biogeogr. 29, 395-410.

Martin T. G. \& Possingham H. P. (2005) Predicting the impact of livestock grazing on birds using foraging height data. $\mathcal{F}$. Appl. Ecol. 42, 400-8.

Masters P. (1996) The effects of fire-driven succession on reptiles in spinifex grasslands at Uluru National Park, northern territory. Wildl. Res. 23, 39-48.

Nash M. S., Bradford D. E., Franson S. E., Neale A. C., Whitford W. G. \& Heggem D. T. (2004) Livestock grazing effects on ant communities in the eastern Mojave Desert, USA. Ecol. Indic. 4, 199-213.

Nicholls A. O. (1989) How to make biological surveys go further with generalised linear models. Biol. Conserv. 50, 51-71.

Patten M. A. \& Bolger D. T. (2003) Variation in top-down control of avian reproductive success across a fragmentation gradient. Oikos 101, 479-88.

Pianka E. R. (1996) Long-term changes in the lizard assemblages in the Great Victoria Desert. In: Long-Term Studies of Vertebrate Communities (eds M. L. Cody \& J. A. Smallwood) pp. 191-216. Academic Press, San Diego, CA.

R Core Development Team (2004) R: A Language and Environment for Statistical Computing. R Foundation for Statistical Computing, Vienna.

Read J. L. (2002) Experimental trial of Australian arid zone reptiles as early warning indicators of overgrazing by cattle. Aust. Ecol. 27, 55-66.

Recher H. R. (2003) WildCountry. Pac. Conserv. Biol. 8, 2212.

Reed D. H. (2004) Extinction risk in fragmented habitats. Anim. Conserv. 7, 181-91.

Ricketts T. H. (2001) The matrix matters: effective isolation in fragmented landscapes. Am. Nat. 158, 87-99.

Sarre S., Smith G. T. \& Meyers J. A. (1995) Persistence of two species of gecko (Oedura reticulata and Gehyra variegata) in remnant habitat. Biol. Conserv. 71, 25-33.
Schlesinger C. A. (1999) The Effect of a Temporally Variable Environment and Grazing on Lizards in Mulga (Acacia aneura) Shrublands on Central Australia. Northern Territory University, Darwin.

Segelbacher G., Hoglund J. \& Storch I. (2003) From connectivity to isolation: genetic consequences of population fragmentation in capercaillie across Europe. Mol. Ecol. 12, 1773-80.

Smith G. T., Arnold G. W., Sarre S., Abensperg-Traun M. \& Steven D. E. (1996) The effect of habitat fragmentation and livestock grazing on animal communities in remnants of gimlet Eucalyptus salubris woodlands in the Western Australian wheatbelt. II. Lizards. F. Appl. Ecol. 33, 1302-10.

Soule M. E. \& Terborgh J. (1999) Continental Conservation: Scientific Foundations of Regional Reserve Networks. Island Press, Washington, DC.

Soulé M. E., Mackey B. G., Recher H. F. et al. (2004) The role of connectivity in Australian conservation. Pac. Conserv. Biol. 10, 266-79.

Steffan-Dewenter I. \& Tscharntke T. (2002) Insect communities and biotic interactions on fragmented calcareous grasslands - a mini review. Biol. Conserv. 104, 275-84.

Stockwell C. A., Hendry A. P. \& Kinnison M. T. (2003) Contemporary evolution meets conservation biology. Trends Ecol. Evol. 18, 94-101.

Stow A. J., Sunnucks P., Briscoe D. A. \& Gardner M. G. (2001) The impact of habitat fragmentation on dispersal of Cunningham's skink (Egernia cunninghami): evidence from allelic and genotypic analyses of microsatellites. Mol. Ecol. 10, 867-78.

Sumner J., Jessop T., Paetkau D. \& Moritz C. (2004) Limited effect of anthropogenic habitat fragmentation on molecular diversity in a rain forest skink, Gnypetoscincus queenslandiae. Mol. Ecol. 13, 259-69.

Swihart R. K., Gehring T. M., Kolozsvary M. B. \& Nupp T. E. (2003) Responses of 'resistant' vertebrates to habitat loss and fragmentation: the importance of niche breadth and range boundaries. Divers. Distrib. 9, 1-18.

Watson D. M. (2002) A conceptual framework for studying species composition in fragments, islands and other patchy ecosystems. F. Biogeogr. 29, 823-34.

Wiegand T., Revilla E. \& Moloney K. A. (2005) Effects of habitat loss and fragmentation on population dynamics. Conserv. Biol. 19, 108-21.

Williams B. L., Brawn J. D. \& Paige K. N. (2003) Landscape scale genetic effects of habitat fragmentation on a high gene flow species: Speyeria idalia (Nymphalidae). Mol. Ecol. 12, $11-20$.

Wilson S. \& Swan G. (2003) A complete guide to reptiles of Australia. Reed New Holland, Sydney.

With K. A. \& Crist T. O. (1995) Critical thresholds in species responses to landscape structure. Ecology 76, 2446-59.

With K. A., Cadaret S. J. \& Davis C. (1999) Movement responses to patch structure in experimental fractal landscapes. Ecology 80, 1340-53.

Yates C. J., Norton D. A. \& Hobbs R. J. (2000) Grazing effects on plant cover, soil and microclimate in fragmented woodlands in south-western Australia: implications for restoration. Aust. Ecol. 25, 36-47. 